Annales Geophysicae (2003) 21: 493-508 (C) European Geosciences Union 2003

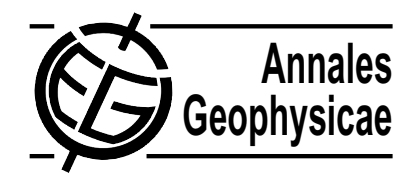

\title{
Ps 6 disturbances: relation to substorms and the auroral oval
}

\author{
M. Connors ${ }^{1}$, G. Rostoker ${ }^{2,6}$, G. Sofko ${ }^{3}$, R. L. McPherron ${ }^{4}$, and M. G. Henderson ${ }^{5}$ \\ ${ }^{1}$ Centre for Science, Athabasca University,Athabasca, AB T9S 3A3 Canada \\ ${ }^{2}$ Department of Physics, University of Alberta, Edmonton, AB T6G 2E1 Canada \\ ${ }^{3}$ Department of Physics and Engineering Physics, 116 Science Place, Saskatoon, SK S7N 5E2 Canada \\ ${ }^{4}$ Institute for Geophysics and Space Physics, University of California, Los Angeles, Los Angeles, CA 90024-1567 USA \\ ${ }^{5}$ Mail Stop D-436 Los Alamos National Laboratory, Los Alamos, NM 87545 USA \\ ${ }^{6}$ Solar-Terrestrial Environment Laboratory Nagoya University, Toyakawa Aichi 442-8507 Japan
}

Received: 19 July 2001 - Revised: 6 June 2002 - Accepted: 19 June 2002

\begin{abstract}
Ps 6 disturbances and associated omega bands are often considered to be part of the phenomenology of the recovery phase of substorms. We note cases of the initiation of Ps 6 activity at or very near the time of onset, either of a substorm expansive phase, a pseudobreakup, or a poleward border intensification. Thus, we claim that Ps 6 disturbances need not be viewed primarily as phenomena of the recovery phase. This produces both the challenge of explaining Ps 6 within a broader context and the opportunity to use Ps 6 observations to better understand magnetospheric phenomenology, including expansive phase onsets. We further examine the position of the causative currents for Ps 6 and find that they may be located at either the equatorward or poleward border of the auroral oval, or within it. In the first case, the relationship of expansive phase onset and time delay to Ps 6 initiation appears to be very short. In the latter case, there is an association with poleward border intensification, but with a measurable time delay. We present HF radar data to discuss how the electric field at onset time favors the growth of Ps 6 current systems.
\end{abstract}

Key words. Magnetospheric physics (Storms and substorms; Electric fields; MHD waves and instabilities)

\section{Association of Ps 6 with substorm phase}

Ps 6 and corresponding auroral omega bands were identified by Saito in the early 1970s (Saito, 1974) as morning sector features associated with substorms. Ps 6 are observed primarily in the declination or eastward ( $D$ or $Y$ ) component of the magnetic field, as observed at the ground, and have amplitudes from 10 to more than $500 \mathrm{nT}$, with a period range of 5 to $40 \mathrm{~min}$ (Saito, 1978). Ps 6 are often referred to as "pulsations", but their generation method remains unknown, although likely involving Kelvin-Helmholtz instability (Connors and Rostoker, 1993). They are not true pulsations directly reflecting the activity of ULF waves in the magneto-

Correspondence to: M. Connors (martinc@athabascau.ca) sphere, as described by Samson (1991), but result from the passage of a current system over observing points (Amm, 1996). Thus, we prefer and make use of the more general term Ps 6 disturbances. Saito noted the association of Ps 6 with substorms in a general way and did not specifically attempt to place Ps 6 in the context of a growth-expansiverecovery phase scenario. However, he did note that each Ps 6 "event" was associated with a Pi2 "event" (Saito, 1978), and he attempted to identify the time delay between the start of the two types of event, finding that the delay is proportional to the longitude difference of the stations where each was observed. Pi2, impulsive pulsations in the 40 to $150 \mathrm{~s}$ period range, are generally accepted to have a close connection to substorm onset (Olson, 1999). Thus, implicit in Saito's attempt to identify time delays after onset was the idea that Ps 6 follow the expansive phase and are causally linked to it. Interestingly, Akasofu's (1964) paper, which defined the concept of auroral substorm phases, mentioned omega bands, now known to be closely associated with Ps 6, as part of the late expansive phase. Over time, this view has changed, and it is widely stated in recent literature (e.g. Opgenoorth et al., 1983, 1994; Pulkkinen et al., 1991a, b, 1998; Baker et al., 1996; Lewis et al., 1997; Jorgensen et al., 1999) that Ps 6 are associated with the substorm recovery phase. Recently, Wild et al. (2000) noted a Ps 6 activation in the morning sector that coincided with onset in the midnight sector, and suggested a follow-up to see whether such an association took place often. Since Ps 6 have figured in the discussion of models such as the near-Earth neutral line model, we regard it as essential for the discussion of substorm models, to clarify at which stage of the substorm cycle Ps 6 and omega bands in fact occur. We present here several cases in which there is direct association between Ps 6 initiation and onset, either of an expansive phase (EP), a pseudobreakup (Koskinen et al., 1993), or of a poleward border intensification (PBI) which is a distinct phenomenon (Lyons et al., 1999).

A typical sequence for Ps 6 observations at an individual observatory is shown in Fig. 1. The upper panel shows the northward component of the interplanetary magnetic field as 

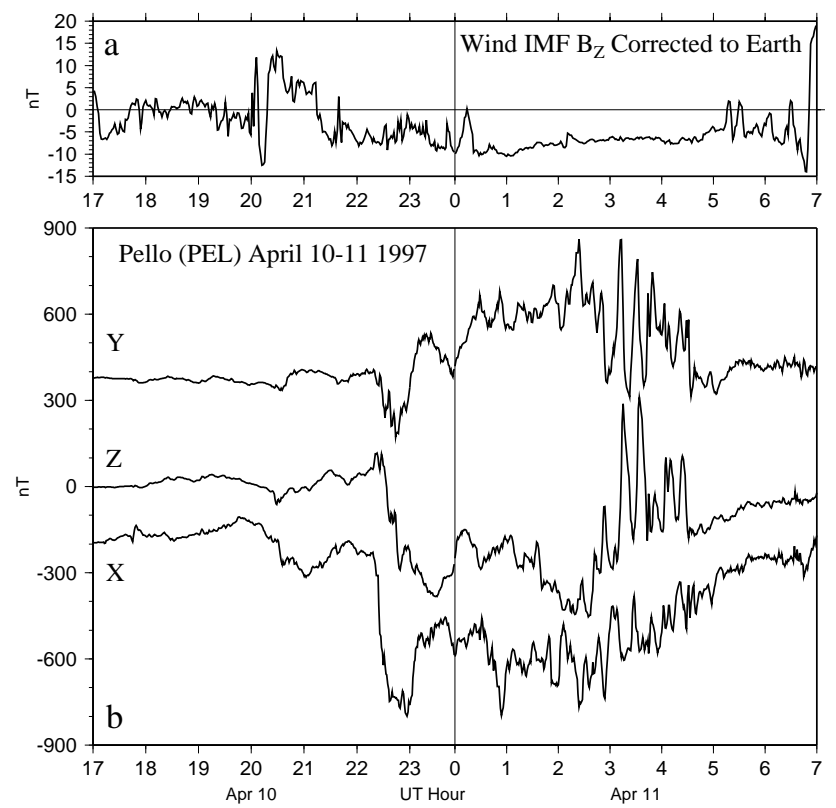

Fig. 1. (a) Northward component of interplanetary magnetic field on 10-11 April 1997 as observed at the Wind spacecraft and propagated to Earth at the solar wind velocity. (b) Magnetogram for Pello, Scandinavia, on 10-11 April 1997. A major onset near this station took place at roughly 22:20 UT 10 April, and Ps 6 signals are seen in the $Y$ and $Z$ components starting at about 03:00 UT on 11 April. Traces have been shifted vertically for clarity.

propagated from the Wind spacecraft to Earth (the earlier part verified by comparison to the IMP-8 spacecraft which was near Earth). Shortly after 21:00 UT on 10 April 1997, the IMF turned southward. A small expansive phase onset took place shortly afterward, at 20:31 UT. A rapid decrease in the northward $(X)$ component, typical of an expansive phase onset as observed at an auroral zone station, is seen at 22:19 UT. Several hours later, close to 03:00 UT on 11 April, a clear Ps 6 event began, with a distinctive eastward $(Y)$ component increase correlated with variations in the downward $(Z)$ component. We regard a clear signature of Ps 6 in the Northern Hemisphere to show a peak in the $Y$ component, while the $Z$ component is increasing with its perturbation passing through zero. Such a signature is expected in a simple model (Kawasaki and Rostoker, 1979) wherein a localized equatorward equivalent current drifts eastward over a morning sector observatory (this model also applies in the Southern Hemisphere but leads to reversed signs of $Y$ and $Z$ perturbation). We do not discuss further the current systems responsible for the ground signature here, but other configurations are possible (Amm, 1996). Examination of a magnetic record such as Fig. 1 could lead one to think that the Ps 6 train is associated with the late recovery phase, since the several hour long negative $X$ bay disturbance declines and the $X$ value returns to pre-disturbance levels. We suggest that such single station observations, showing a time lag between onset signatures and the occurrence of Ps 6 at one location, can be misleading. Onset signatures are generally seen when a station is

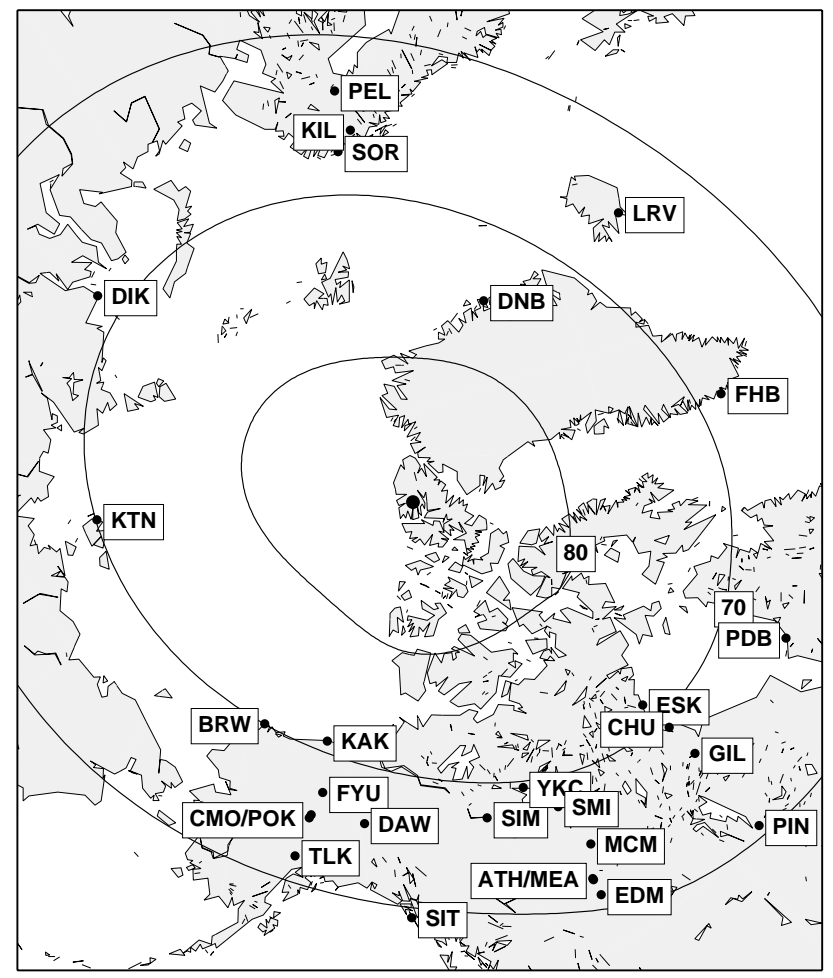

Fig. 2. Map showing geographic locations of magnetic stations used. Labels correspond to codes in Table 1. Corrected geomagnetic (CGM) latitude lines for 1997 at $+60^{\circ},+70^{\circ}$, and $+80^{\circ}$ are shown with labeling along the CGM $0^{\circ}$ meridian.

in the midnight sector, while Ps 6 disturbances are normally observed in the morning sector. As a station rotates from the midnight local time sector into the morning, the signature of activity it detects will change from onsets to Ps 6 disturbances. The direction of rotation of the Earth, rather than any necessary sequence within a substorm, determines that a single station may first see onset signatures and then Ps 6 . Seeing this pattern at a single station thus does not necessarily mean that Ps 6 are associated with recovery phase. We concur with Pellinen and colleagues (1992) in stressing the importance of using simultaneous ground magnetic observations from many local time sectors when attempting to unravel the complex global phenomenology of substorms. We have further found radars to be very useful since they now provide extensive coverage of the auroral zone (Greenwald et al., 1995), and have included analysis of Pi2 pulsations to assist in the identification of onsets. For one event we have used satellite imaging, which is a useful adjunct when analyzing complex magnetic records. When this global approach was taken for several Ps 6 events, we found a close temporal relation between initiation of Ps 6 disturbances in the morning sector and onsets in the midnight sector, as we now proceed to discuss. 
Table 1. Auroral zone stations

\begin{tabular}{|c|c|c|c|}
\hline Station & Code & Geodetic E Longitude & Geodetic N Latitude \\
\hline Kilpisjärvi(EISCAT) & KIL & 20.7 & 69.1 \\
\hline Sørøya (EISCAT) & SOR & 22.2 & 70.5 \\
\hline Pello (EISCAT) & PEL & 24.1 & 66.9 \\
\hline Dikson (Russia) & DIK & 80.6 & 73.5 \\
\hline Kotel'nyy (210 meridian) & KTN & 137.7 & 75.9 \\
\hline Talkeetna (Alaska) & TLK & 209.9 & 62.3 \\
\hline College (Alaska) & $\mathrm{CMO}$ & 212.2 & 64.9 \\
\hline Poker Flat (Alaska) & PKR & 212.5 & 65.1 \\
\hline Fort Yukon (Alaska) & FYU & 214.7 & 66.6 \\
\hline Kaktovik (Alaska) & KAK & 216.4 & 70.1 \\
\hline Sitka (Alaska) & SIT & 224.7 & 57.1 \\
\hline Dawson (CANOPUS) & DAW & 220.9 & 64.1 \\
\hline Victoria (Canada) & VIC & 236.6 & 48.5 \\
\hline Fort Simpson (CANOPUS) & SIM & 238.8 & 61.8 \\
\hline Yellowknife (Canada) & YKC & 245.5 & 62.4 \\
\hline Edmonton (Canada) & EDM & 246.5 & 53.5 \\
\hline Meanook (Canada) & MEA & 246.6 & 54.6 \\
\hline Athabasca (Canada) & ATH & 246.7 & 54.7 \\
\hline Fort Smith (CANOPUS) & SMI & 248.1 & 60.0 \\
\hline Ft. McMurray (CANOPUS) & $\mathrm{MCM}$ & 248.8 & 56.7 \\
\hline Gillam (CANOPUS) & GIL & 265.4 & 56.4 \\
\hline Churchill (CANOPUS) & $\mathrm{CHU}$ & 265.9 & 58.8 \\
\hline Eskimo Point (CANOPUS) & ESK & 266.0 & 61.1 \\
\hline Pinawa (CANOPUS) & PIN & 264.0 & 50.2 \\
\hline Poste-de-la-Baleine (Canada) & PDB & 282.2 & 55.3 \\
\hline Paamiut (Greenland) & FHB & 310.3 & 62.0 \\
\hline Daneborg (Greenland) & DNB & 339.9 & 74.2 \\
\hline Leirvogur (Iceland) & LRV & 338.4 & 64.2 \\
\hline
\end{tabular}

Table 2. Pi2 stations

\begin{tabular}{llcc}
\hline Station & Code & Geodetic E Longitude & Geodetic N Latitude \\
\hline Los Alamos, NM (USA) & LAL & 253.6 & 35.9 \\
USAF Academy (USA) & AFA & 255.1 & 39.0 \\
Melbourne, FL (USA) & FIT & 279.3 & 28.0 \\
JHU APL, MD (USA) & APL & 283.1 & 39.1 \\
Jacksonville, FL (USA) & JAX & 278.3 & 30.3 \\
\hline
\end{tabular}

\section{Association of Ps 6 with onset}

Saito (1978), using bays and Pi2 as signatures of the expansive phase onset, showed cases in which the start of Ps 6 followed onset by up to an hour and others in which the two events were simultaneous at one station. He concluded that the delay of Ps 6 initiation in a given local time sector was proportional to that sector's longitudinal distance from the onset region. Mravlag et al. (1991) studied optical, magnetic, and radar data from a wide longitudinal range and found that Ps 6 initiation seemed to be simultaneous over that range and thus unrelated to longitude. This is contrary to Saito's result, and they did not remark on any causal relation to ex- pansive phase onset. Pellinen et al. (1992) noted the coincidence of omega bands and Ps 6 with evening sector activity increases in general, and the simultaneous occurence in a local auroral activation and the appearance of omega bands in at least one case. Connors (1998), in a study of general onset phenomenology, using primarily global ground magnetic data sets, noted activation of Ps 6 appearing to coincide with onsets, without necessarily a time delay associated with distance from the onset location. In a recent study of one event using radar data, Wild et al. (2000) noted that Ps 6 activation in the morning sector coincided with onset in the midnight sector.

We show here that under certain circumstances, coinci- 


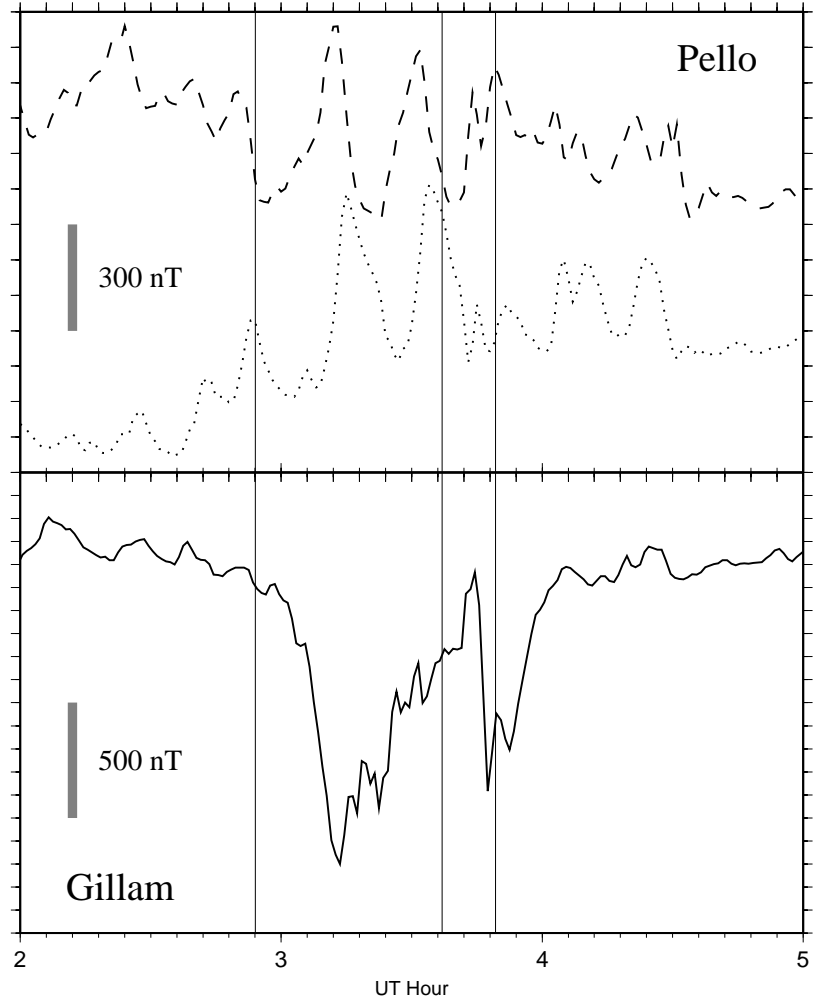

Fig. 3. $X$ component perturbation from Gillam (solid) and $Y$ (dashed) and $Z$ (dotted) component perturbations from Pello between 02:00 UT and 05:00 UT on 11 April 1997. Traces have been shifted vertically for clarity. Change in pulsational character of Ps 6 takes place at the time of onset, despite the longitudinal separation of the stations. In subsequent non-colored diagrams the components are indicated as here, with a solid line for $X$, a dashed line for $Y$, and a dotted line for $Z$.

dence with onset is normal and that Ps 6 activation is part of the overall onset phenomenology. A relation between onset, generally in the near-midnight sector, and Ps 6 activation, appears to exist both for expansive phase onsets and for poleward border intensifications. We present here four events during which there were cases of Ps 6 activation simultaneous with onset, even at stations distant from the onset region. The association with onset identified by Saito (1978) is thus borne out. We find indications that a delay related to distance from the onset region may exist for Ps 6 activations associated with poleward border intensifications, but here we do not systematize that delay in a general way. We did not find a delay associated with Ps 6 activation associated with expansive phase onset. Locations of auroral zone stations used in this study are listed in Table 1, and many of their locations are depicted in Fig. 2. We used mid-latitude stations recording data every second, listed in Table 2, to identify Pi2 pulsations and specify onset times as accurately as possible. Vector magnetic fields were recorded at these locations along the $X, Y$, and $Z$ directions as defined above, in the local magnetic system whose horizontal components we designate $X_{M}$ and $Y_{M}$, or as horizontal field $H$ with declination $D$.

\section{$2.1 \quad 10-11$ April 1997 event}

Beginning shortly after 21:00 UT (as corrected to an Earth location) on 10 April 1997, the IMF was basically southward for nearly $10 \mathrm{~h}$ with values of about -5 to $-8 \mathrm{nT}$, as seen in the top panel of Fig. 1. A major expansive phase onset took place at 22:19 UT on 10 April and magnetic conditions at most nightside stations for many hours after this were disturbed. Figure 1 also shows perturbations at the Scandinavian station Pello during the relevant time period. There is a clear signature of onset at 22:19 UT, followed by a period of depressed $X$ component values without further similarly distinct onsets. Currents of 1 to $2 \mathrm{MA}$ in the morning sector westward electrojet were inferred through forward modeling for this period. This involves variation of electrojet parameters in a model until an optimal match between model predictions and observed ground perturbations is obtained (Kisabeth, 1979). This technique has been automated (Connors, 1998) based on the Levenberg-Marquardt algorithm (Press et al., 1992), and will be described in detail elsewhere. This period of enhanced activity during predominantly southward IMF conditions had ground signatures resembling those of a steady magnetospheric convection (SMC) interval as described by Sergeev and co-workers (1996). Spacecraft data from the magnetotail are lacking for this event. Although we thus cannot compare to the tail characteristics of SMC intervals that Sergeev et al. (1996) listed, for this event we have good Polar UVI LBHL (Brittnacher et al., 1997) images available and have inspected them. In conjunction with ground magnetic data they show that much of this period was characterized by a double auroral oval with transient activations on the poleward border. A second major expansive phase onset at 02:54 UT on 11 April took place in the evening sector over the Churchill line of the CANOPUS array. Simultaneously, large Ps 6 disturbances started in the morning sector as observed at IMAGE array stations in Scandinavia. Figure 3 emphasizes this by plotting the onset signature ( $X$ bay) from Churchill meridian station Gillam, together with the $Y$ and $Z$ perturbations from Scandinavian station Pello. Ps 6 characteristics of correlated $Y$ and $Z$ perturbations were present in the IMAGE array magnetic data before the 02:54 UT onset, particularly the more northerly ones. However, their amplitude strengthened and the correlation of $Y$ and $Z$ became greater, shortly after onset. The onset timing shown was determined, independently of magnetic signatures, from UVI images.

Having noted this connection between midnight and morning sector activity, we returned to the satellite image sequence to attempt to find other evidence of a relationship between onsets and Ps 6 activity. We note three distinct types of "onset" whose character may be established through inspection of the magnetic data in conjunction with the images. These include expansive phase onsets, involving activation at the equatorward border of the auroral oval followed by poleward expansion (Rostoker, 2002) and pseudobreakups (Koskinen et al., 1993), which are similar but do not expand in a significant way. The third type is the poleward border 
intensification or PBI (Lyons et al., 1999) that appears to be a separate phenomenon and, as the name implies, takes place at the poleward border of the auroral oval. All of these onsets have among their magnetic signatures a decline in the $X$ component near the region of activation, and changes in the other components that are consistent with enhancement of ionospheric current. On satellite images they are signaled by a brightening in the region of activation. Through study of magnetic signatures at many stations, the location of activations with respect to the auroral oval may be determined provided that adequate data is available. On a global scale this proves to be difficult to obtain. For this particular event, satellite images allow activation locations to be determined unambiguously. Another ambiguity that is resolved through the use of satellite images is that associated with poleward motion of the border of the electrojet. As the electrojet moves poleward after an EP onset, it causes the $X$ component to decline, sometimes abruptly, at successively more poleward observing points. This decline can be easily misinterpreted as an immediate signature of the onset, leading to inaccurate timing. We note below a similar effect taking place after a PBI as well.

The next onset signature visible in Fig. 3 was that of a large amplitude PBI, near Gillam at 03:37 UT. At this time, the Ps 6 pulsation amplitude declined dramatically at all IMAGE stations. From magnetic data alone, it would have been difficult to distinguish one onset as EP and the next as PBI. However, the satellite images show that the 03:37 UT onset took place at the poleward border of the auroral oval, and allowed the best onset time to be determined. The magnetic perturbation at Gillam was delayed with respect to this onset time since the region carrying current moved poleward after the PBI started. In both cases, with about $8 \mathrm{~h}$ of MLT separating the onset region from the meridian featuring strong Ps 6 activity, there was a pronounced relationship between onset times at the more westerly station and changes in the Ps 6 character in the morning sector. There did not appear to be a significant time delay between expansive phase onset and the change in Ps 6 character, whereas there did appear to be a delay between onset at the poleward border and such a change.

Figure 4 presents $X$ component perturbations from Scandinavia, Greenland, and Canada, along with $Y$ component perturbations from Scandinavia and Russia. We have used Polar UVI images as the determinant of onset timing and type, and the results of this determination are presented as vertical bars. Although images were acquired during this event at a rate of one every 36 seconds (G. Germany, private communication, 2002), we had available for this large time period only images from only one filter (LBHL), making the best time resolution approximately three minutes. We intend to present multispectral analysis with higher time resolution at a later time, but feel that the cadence used here, along with one-minute spacing on magnetic data, is sufficient for the initial investigation of the relationships between onsets and very low frequency signals like Ps 6 . The general nature of activity can also be distinguished using the images,

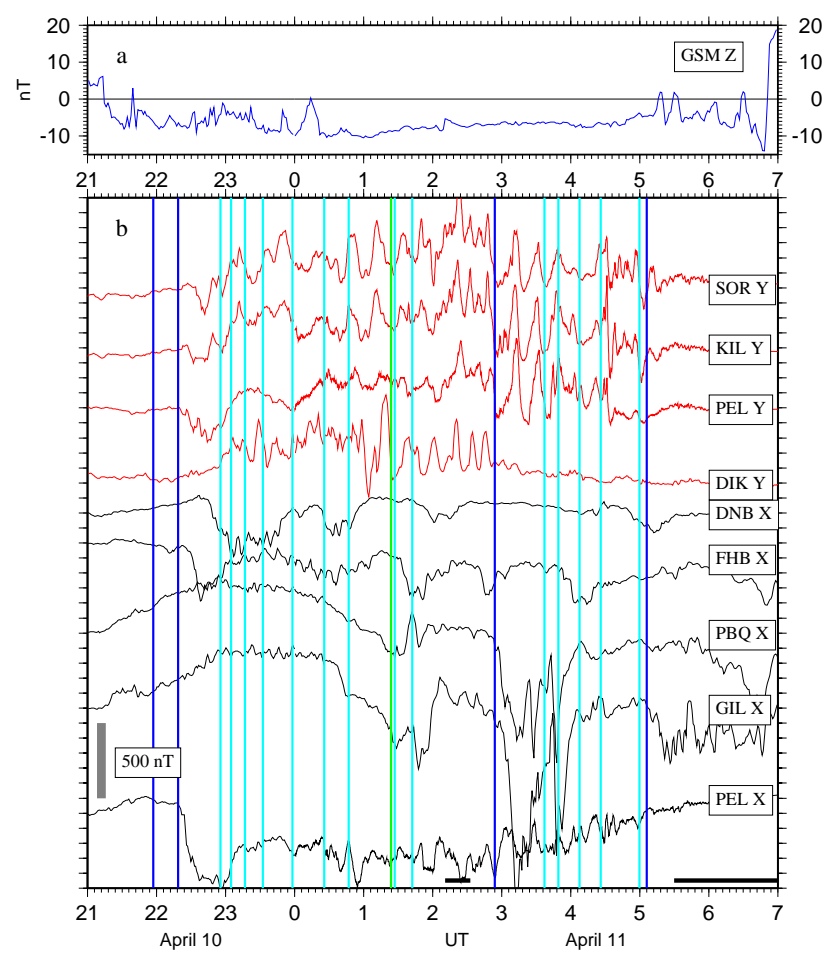

Fig. 4. Overview of onset and Ps 6 activity on 10 and 11 April 1997. Vertical lines indicate the times of expansive phase onsets in blue, PBIs in cyan, and one pseudobreakup in green, as determined from Polar UVI images. Line width corresponds to the 3-min uncertainty inherent in the image data set used. $X$ component perturbations are depicted in the lower part of the plot in black, and $Y$ component in the upper part in red. $Y$ component at DIK (Dixon) appeared to be supplied with an erroneous scale and was scaled by 0.1 for plotting. Short horizontal lines near the bottom indicate two data gaps in the Polar UVI data set used. The useful imaging sequence ended at about 05:30 UT on 11 April.

including periods when the auroral oval appears to be doubled. During the period of $10 \mathrm{~h}$ shown on Fig. 4, only four expansive phase onsets and one pseudobreakup took place, as identified from the satellite images, which had a good view of the midnight sector throughout. This confirms the results of inspection and inversion of ground magnetic data as described above. There were, however, fourteen clearly identifiable PBI episodes. The lack of expansive phase activity and the prevalence of PBI is characteristic of SMC, as mentioned above in reference to the interpretation of ground data. The onset at 21:57 UT has been classified as an expansive phase, since poleward motion was seen in the images: its magnetic signature was subdued, not exceeding $100 \mathrm{nT}$ at LRV, which was the station best placed to detect it. The associated data are not shown. The major expansive phase onset at 22:19 UT had classical signatures at many stations (of which PEL shows it most clearly in Fig. 4, with several other stations showing smaller and delayed signatures) and led to the formation of a doubled auroral oval. Starting at 22:55 UT, a series of discernable PBIs took place. We emphasize the word "discernable", since the poleward expanding poleward 
border of the electrojet was bright during the period following onset, until this first recorded PBI and from this data set we cannot eliminate the possibility that PBIs took place during the poleward motion. In addition, it is likely that smaller PBIs, not easily detected on satellite images, also took place. Detecting magnetic signatures during the poleward motion of the poleward border, or from small PBIs, would similarly be difficult. There were no major expansive phase intensifications after the 22:19 UT event, until 02:54 UT on 11 April. We note that this event was also followed by a period without discernable PBIs for about $45 \mathrm{~min}$, and again stress that, although this may be an indication of a physical process, we cannot exclude that PBIs did in fact take place while the poleward border of the electrojet moved poleward. At 01:24 UT on 11 April, a pseudobreakup took place, with subdued magnetic signals. A final expansive phase took place at 05:06 UT 11 April in a greatly expanded auroral oval. From magnetic signatures at PIN and MCM it may be deduced that this onset took place near $58^{\circ}$ magnetic latitude.

We now turn to the association between onsets and Ps 6 initiations that Fig. 3 suggests. The two onsets near the beginning of the active period did not appear to be accompanied by the initiation of Ps 6 activity. Both were EP onsets, a minor one at 21:57 UT, and a major one at 22:19 UT. Although there was $Y$ component activity at stations east of the onset regions, it was not correlated with the $Z$ component in the way Ps 6 signals must be. The first true Ps 6 signals during this event started at 00:40 UT (11 April), as detected at Scandinavian stations (such as SOR in Fig. 4), followed by activation further east at DIK at 01:00 UT. The pseudobreakup at 01:24 UT appeared to take place at the same time as minor changes in $Y$ component behavior at several of the stations showing Ps 6 activity, but the evidence of this in Fig. 4 is not strong. As noted in relation to Fig. 3, however, the expansive phase at 02:54 UT, which was centered in North America, coincided with a dramatic change in Ps 6 activity in the morning sector in Scandinavia and, as may be seen in Fig. 4, also in Russia. In Scandinavia, the activity became more coherent, with a longer period and greater amplitude. At Dixon, the amplitude of Ps 6 activity declined dramatically, most notably in the $Y$ component ( $Z$ is not shown). There does not appear to be a time delay between the onset and the change in pulsational behaviour, although the large amplitude Ps 6 appear to build up over a period of a few minutes. The final expansive phase onset took place at 05:06 UT and did not appear to have a direct and immediate correlation with changes in Ps 6 activity. Within a few minutes, however, Ps 6 activity died away. We note that the IMF turned briefly northward shortly after this onset as well. Upon its return to negative values, and with a high dynamic pressure (over $10 \mathrm{nPa}$ ) until the northward turning, magnetic activity continued to be strong, as evidenced by the GIL and PBQ traces in Fig. 4. However, we did not detect Ps 6 activity during the period after about 05:15 UT, when the last Ps 6 pulse died away at SOR, and the imaging sequence was also not useful in detecting activity after that time. Thus, one major EP onset in the middle of a period of steady convection is unambigu- ously associated with a strong Ps 6 enhancement, without a noticeable time delay between its occurrence in the midnight sector and the change in $Y$ component behavior in the morning sector. Since Ps 6 signatures were present before this EP onset, we now examine whether they started abruptly and whether an another onset was involved. This possibility can be investigated using images and magnetic data.

Figure 5 shows a short sequence of UVI LBHS images from Polar for the time period relevant to the 00:26 UT 11 April PBI. Such images indicate primarily the locations of soft electron precipitation (Brittnacher et al., 1997). The moving patch of auroral luminosity ejected from the PBI is reminiscent of those discussed by Henderson et al. (2001), although not apparently associated with north-south aligned auroral forms. The motion of this patch is eastward at $1.0 \mathrm{~km} / \mathrm{s}$, as measured from the LBHS images, once the motion is clearly established. This is comparable to the speed of luminous patches that Connors and Rostoker (1993) associated with the equatorward boundary of the auroral oval, and to the convection drift velocity in active times (Amm, 1996). The motion of this patch may be traced in the images to the longitude of the Scandinavian stations whose magnetic signatures are shown in Fig. 4. At the time of arrival at that longitude (00:41 UT), Ps 6 pulsations began there. We further note that extrapolation of the motion to the longitude of Dixon would make the auroral patch arrive close to the time of the initiation of Ps 6 there shortly after 01:00 UT. Whether this extrapolation is justified could not be verified with the images presently available to us. We can say that, at least in the case of the Scandinavian stations, and possibly in the case of Dixon as well, the arrival of this patch of luminosity, which had an origin in a PBI, coincided with the start of Ps 6. The time delay to initiation of Ps 6 after onset is not inconsistent with the claim of Saito (1978) that there is a time delay between Pi2 (i.e. onset) and the start of Ps 6 pulsations. In this case the time delay was associated with a PBI and not an EP onset. Lyons et al. (1999) showed that Pi2 bursts in the auroral zone were associated with PBI activity and recently, Sutcliffe and Lyons (2002) have demonstrated mid-latitude Pi2 associated with PBIs under otherwise quiet conditions. Thus, we suspect that in cases involving a time delay from Pi2 onset, Saito may, in fact, have examined Ps 6 associated with PBIs. We noted above (Fig. 3) that an EP onset appeared to coincide with a change in Ps 6 behavior without delay, while a large PBI appeared to have a delay before the response in the morning sector. In the present case, the delay from PBI to Ps 6 activation appears to be longer (15 min versus 6 to 10 ) than in the previous case, despite the eastern edge of the PBI luminosity being in much the same location as that of the earlier PBI.

We have noted two instances of association between PBIs and the initiation of a train of Ps 6 pulsations. However, during this event, there are more PBIs than there are changes in $Y$ component behaviour. Thus, we conclude that not all PBIs produce changes in Ps 6 activity. Similarly, there appear to be more individual Ps 6 pulses than there are PBIs, so that we do not feel that PBIs relate on a one-to-one basis with Ps 6 

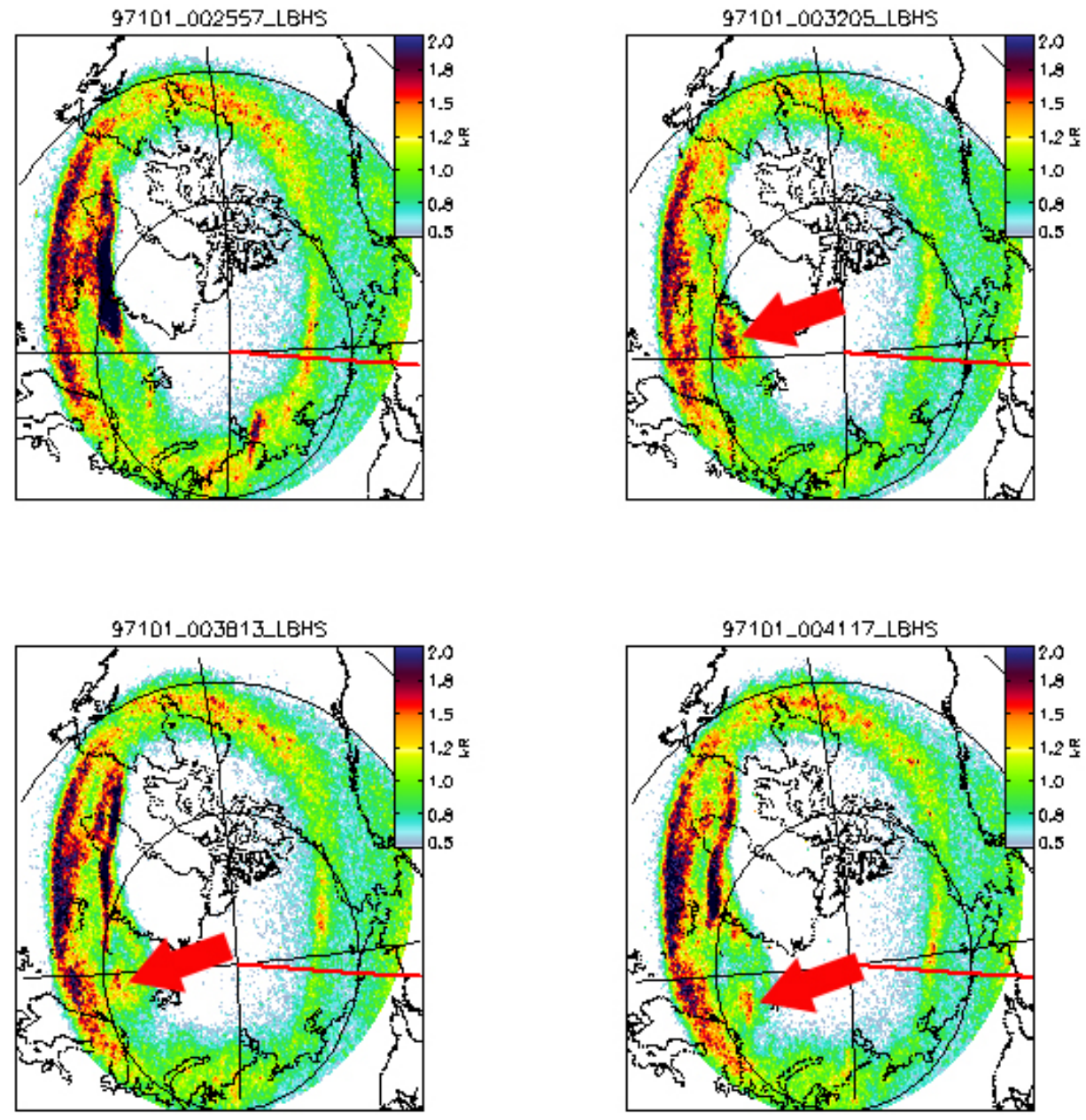

Fig. 5. Polar UVI view of a drifting patch of auroral luminosity in the LBHS band (140-160 nm). At upper left is an image corresponding to initiation of a PBI at 00:26 UT on 11 April 1997. In the image to the upper right, at 00:32 UT, a bright patch is visible $E$ of (below) the Greenland coast. By 00:38 UT, the patch had drifted yet further eastward (lower left). Finally, its arrival in the meridian of the IMAGE stations (lower right) at 00:41 UT corresponded to the time of initiation of Ps 6 pulsations at those stations.

pulses, but rather that under some circumstances, both PBIs and expansive phase onsets are associated with the initiation of a train of Ps 6 . We now proceed to look for other instances of possible onset - Ps 6 relationships.

\subsection{February 1999 event}

Ground stations detected a sudden commencement (SC) at roughly $02: 50$ UT on 18 February 1999 . The WIND spacecraft, located at $X_{\mathrm{GSM}}$ of $-9.5 R_{E}$ and $Y_{\mathrm{GSM}}$ of roughly $-45 R_{E}$, detected nearly simultaneously an increase in solar wind pressure from about 1 to $8 \mathrm{nPa}$, and a speed from below 400 to $650 \mathrm{~km} / \mathrm{s}$. The solar wind remained disturbed until about 17:00 UT, with negative $B_{Z}$ of -5 to $-20 \mathrm{nT}$ from 03:12 UT until about 10:30 UT, whereupon a northward turning to values averaging $15 \mathrm{nT}$ took place, terminating the period of interest here. During this disturbed period, extremely large negative $X$ perturbations of magnitude, up to $2500 \mathrm{nT}$, were observed at nightside stations, as seen in Fig. 6, where the SC signature is also clear. This period was characterized by numerous sharp $X$ component bays, characteristic of substorm expansive phase onsets. In addition to the discrete features, most nightside stations, and particularly those at lower magnetic latitudes, showed a broader envelope of depressed $X$ component values. It is well known (Liou et al., 1998) that magnetic bays can be misleading in determining onset timing, but useful satellite images were not available. Since this disturbed period features numerous bay-like features, we examined a large set of data from nightside auroral and subauroral stations, optical data from the CANOPUS network, and Pi2 pulsations as onset indicators (Olson, 1999). In the latter case, the onset time was determined using data from mid-latitude North American stations listed in Table 2, by determining the envelope of the Pi2 signal at multiple stations 

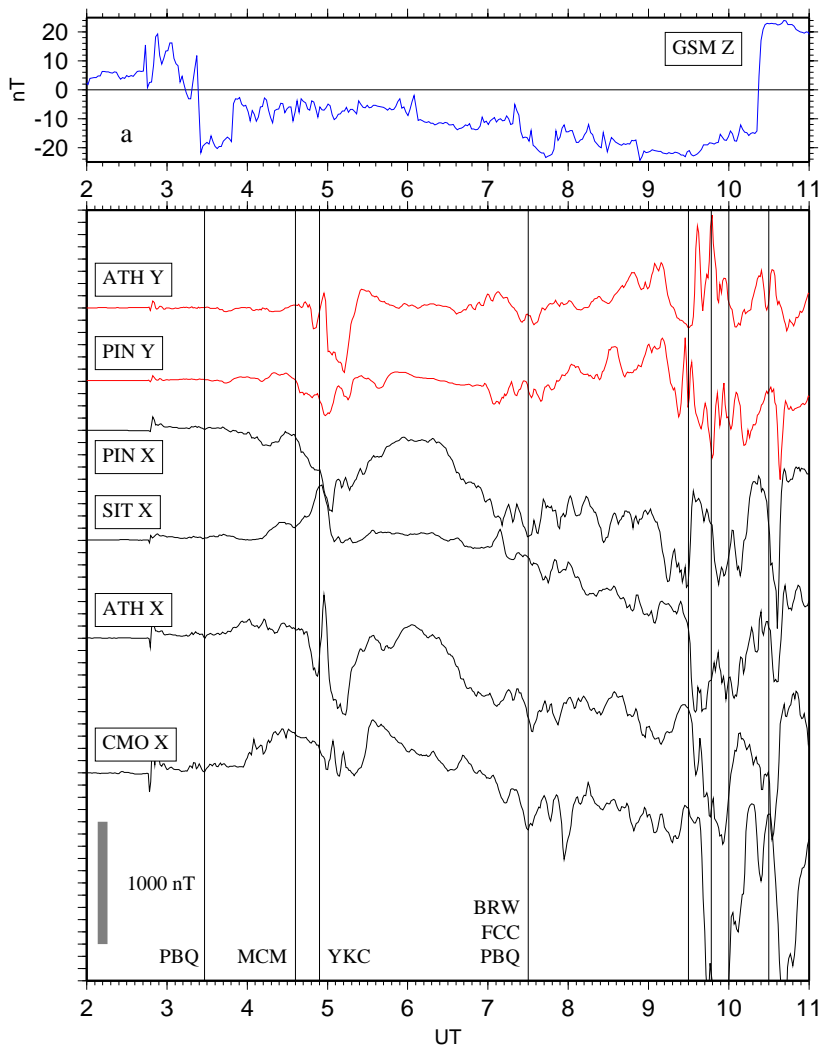

Fig. 6. (a) Northward component of interplanetary magnetic field as observed at the Wind spacecraft on 18 February 1999 and propagated to Earth at the solar wind velocity. (b) Overview of onset and Ps 6 activity on 18 February 1999. Onset times are indicated by vertical lines. For the earlier onsets, times were determined from Pi2 records and a sharp $X$ bay was verified at the stations listed near the bottom of each vertical line.

(Kepko and McPherron, 2001). The earliest onset activity, as indicated by the Pi2 signal, was at 03:11 UT; however, the earliest onset identifiable in the $X$ component magnetic data (at Leirvogur, LRV) was at 03:28 UT. A second Pi2 onset took place at 04:36 UT with near-simultaneous bay activity and a second major onset at 04:54 UT. Both of these intervals of activity featured sustained power in the Pi2 band for about $20 \mathrm{~min}$ and neither appeared to be associated with significant Ps 6 activity. A sharp onset in the Churchill sector at 07:30 UT also did not appear to correlate with the start of Ps 6 activity, although there were some Ps 6-like signatures slightly before the time of onset. This onset does appear to have initiated a period of activity similar to SMC (Sergeev et al., 1996), as evidenced by the depressed values of the $X$ component from 07:00 UT to slightly past 09:00 UT, seen in Fig. 6. We did not find evidence of expansive phase onsets during this interval, either from inspection of magnetic data directly, nor from Pi2 analysis, despite a high level of variation in the magnetic field. During this period, $Y$ component positive perturbations of as much as $1000 \mathrm{nT}$ were observed but their duration of roughly $1 / 2 \mathrm{~h}$ and their lack of correlation to the $Z$ component do not allow us to classify them as

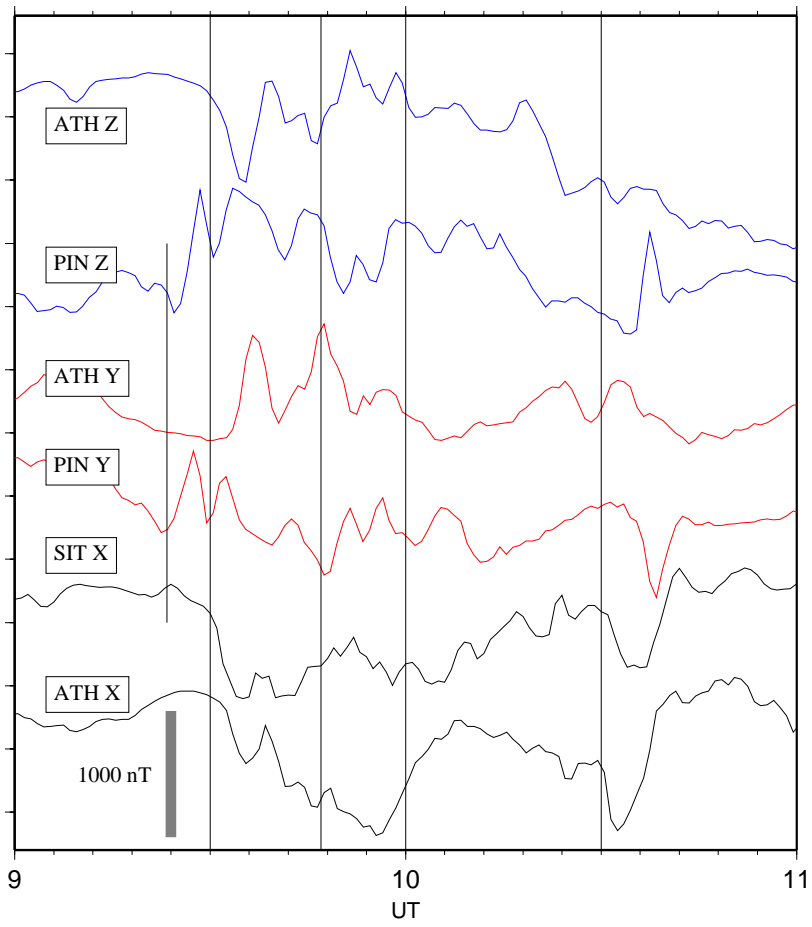

Fig. 7. Magnetic perturbations at Alaskan station, Sitka, western Canadian station Athabasca, and central Canadian station Pinawa, from 09:00 to 11:00 UT on 18 February 1999. Long vertical bars indicate onset times as determined from $\mathrm{Pi} 2$ analysis. A shorter vertical bar at 09:24 UT indicates the time of a change in $X$ observed at Sitka and initiation of Ps 6 at Pinawa.

Ps 6. The latter part of this period featured equatorward motion of the westward electrojet as may be inferred from the return of $X$ perturbations to near-baseline values at the highest latitude stations while it became more negative at the two most southerly.

At 09:24 UT a clearly defined Ps 6 pulse pair was detected at Pinawa, the most southern of the CANOPUS stations (see Fig. 6). Although several stations showed changes in magnetic behavior at this time, we could not identify an onset as having taken place at any station including Pinawa itself. An all-sky camera and meridian scanning photometer at Gillam detected activation of $630.0 \mathrm{~nm}$ emission well south of that station shortly before 09:30 UT, and we associate this with the Ps 6 initiation. At 09:30 UT, an onset took place at low latitude as recorded at Sitka, Athabasca/Meanook, and a temporary station at Edmonton, with strong Ps 6 signal at the latter stations. The disturbances started at 09:30 UT, as shown in Fig. 6, although the Pi2 signal strengthened only slightly later, at 09:32 UT. At this time large $X_{M}$ bays $(-1500 \mathrm{nT})$ were observed at these stations, while $Z$ perturbations, referred to pre-disturbance levels, were slightly positive with brief negative excursions associated with the Ps 6. Data from Ft. McMurray further north also showed positive $Z$ at the time of this onset, but little $X$ perturbation, suggesting a location for the onset currents near or equatorward of Athabasca. Roughly $-500 \mathrm{nT}$ of $X$ perturbation was also recorded at this 

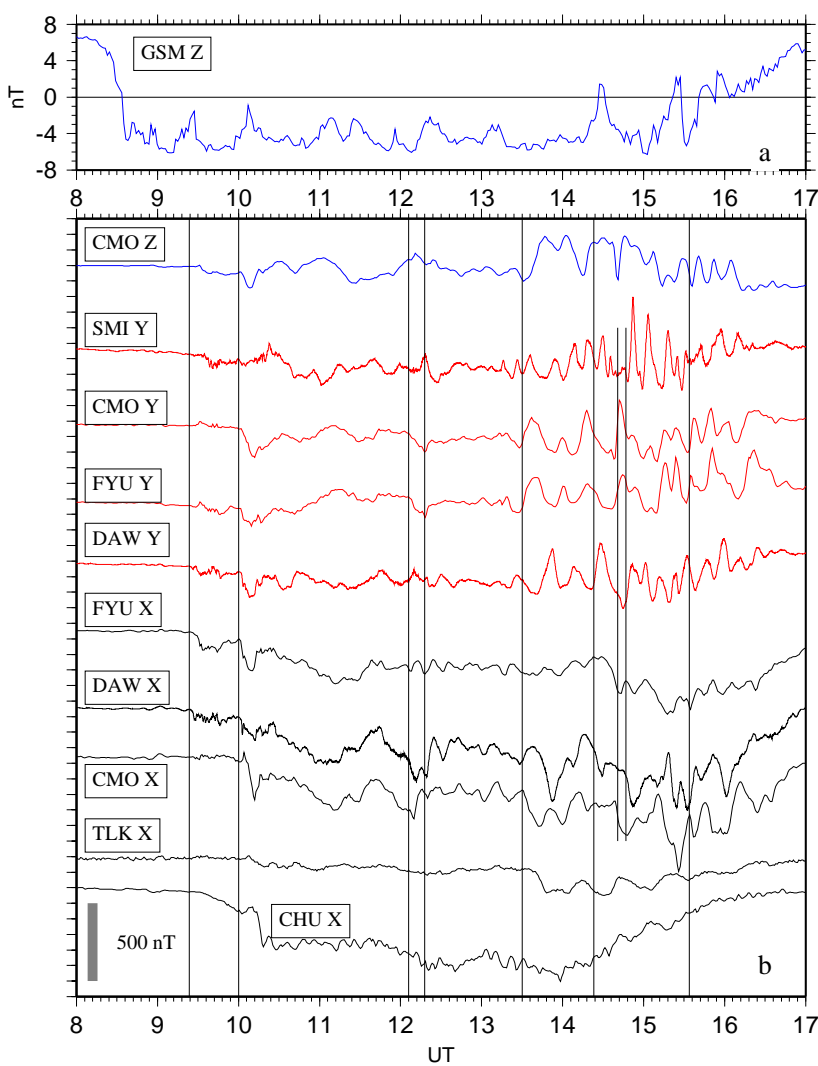

Fig. 8. (a) Northward component of interplanetary magnetic field as observed at the Wind spacecraft on 27 April 2000 and propagated to Earth at the solar wind velocity. (b) Overview of onset and Ps 6 activity on 27 April 2000. Onset times determined from Pi2 are indicated by vertical lines. Shorter vertical lines at 14:41 UT and 14:47 UT indicate other activations when Pi2 bursts were frequent and a unique time determination could not be done.

time (with comparable negative $Z$ perturbation) at Victoria (slightly off the map of Fig. 2), supporting the southerly location of the onset current. Onset signatures at Alaskan stations more northerly than Sitka were delayed slightly. Two further onsets were indicated by the Pi2 data, one at 09:47 UT and one with a weaker signal at 10:00 UT. The 09:47 UT onset appears to have been at relatively low latitude and to have reinitiated Ps 6 activity at Pinawa (see Fig. 7). At 10:00 UT, a sharp onset at higher latitude was observed at Eskimo Point in the Churchill sector, and Fort Simpson and Fort Smith further west. Perturbations in the $Y$ and $Z$ components commenced at these stations at that time, although these did not have a definitive Ps 6 signature (specific $Y-Z$ correlation as described above) and are not shown. We also note a decline in Ps 6 activity at Pinawa and Athabasca/Edmonton at this time (Fig. 7). The final onset that we consider took place at 10:30 UT, and seems to have been associated with dramatic changes in the solar wind. There was a rapid change from $-20 \mathrm{nT}$ to $+20 \mathrm{nT}$ in the $B_{Z}$ component (see Fig. 6a) and a dynamic pressure increase from 5 to nearly $20 \mathrm{nPa}$ associated with a similar factor increase in density. We did not note specific Ps 6 activation associated with this onset, although large changes in the $Y$ and $Z$ components observed at many ground stations did ensue.

From this complex period of activity we can make some inferences about the relation of Ps 6 activation and expansion phase onsets. Several onsets were noted that did not appear to coincide with Ps 6 activity. An extended period without clear-cut onsets preceded the earliest manifestation of clear Ps 6 pulsations, which was at low latitude. Their initiation preceded an onset by about $5 \mathrm{~min}$ at low latitude. When this onset did take place, Ps 6 again was excited at low latitude. A second onset at low latitude affected the character of the Ps 6 disturbances, but they continued. A subsequent onset at higher latitude brought about the cessation of the Ps 6 at low latitude and caused a change in the character of $Y$ and $Z$ component fluctuations at higher latitude. In these cases an onset took place at the same time as a change in pulsational character, and the onset currents and those associated with Ps 6 can be inferred to be at the same relative latitudinal positions within the electrojet. Although we have cited a case in which the Ps 6 activation preceded onset, we cannot completely rule out an earlier onset time from the limited data available. In any case we would not consider this Ps 6 activation to be characteristic of the recovery phase from the preceding active period since the auroral oval was moving equatorward, not poleward, and the IMF $B_{Z}$ was still strongly southward. We infer that Ps 6 can be associated with onset and that their latitude of activation is associated with the latitude of the onset.

\subsection{April 2000 event}

A southward turning was observed at the Earth-Sun Lagrange point $\left(X=223 R_{E}\right)$ by the ACE spacecraft, at $X=82 R_{E}$ by Wind, and at $X=30 R_{E}$ by IMP-8, leading to a consistent interpretation that it was observed at Earth at 08:30 UT on 27 April 2000. An increase in $\mathrm{Pi} 2$ power was observed at 08:29 UT, which we do not classify as an onset signature. With predominantly negative IMF $B_{Z}$ of about $-5 \mathrm{nT}$ until about 15:40 UT, and solar wind speed and density at near-nominal values of roughly $400 \mathrm{~km} / \mathrm{s}$ and 10 protons/cc through most of this period, a convection bay (Pytte et al., 1978; Sergeev et al., 2001) resulted. Figure 8 shows the solar wind $B_{Z}$ and relevant ground magnetic fields. Smooth decreases in the $X$ component that we associate with the growth phase took place in the Churchill meridian starting at 09:00 UT. However, the earliest discrete magnetic field effects identified were sharp decreases of roughly $50 \mathrm{nT}$ in the $X$ and $Z$ components at Alaskan stations Fort Yukon and nearby Dawson at 09:25 UT. We interpret these as being due to a westward ionospheric current north of the stations, but do not have magnetic data from that area. A sharp increase in Pi2 pulsational power at 09:25 UT also indicates the time of onset. Due to weak magnetic signal before the activation, we cannot identify the position of this enhanced current relative to pre-existing growth phase currents, whose signature did not appear as strong in the Alaska sector as it was on 
the Churchill meridian (where it was as much as $100 \mathrm{nT}$ at 09:30 UT). As observed by most CANOPUS stations, the $X$ component negative bay that started at 09:00 UT lasted until 16:30 UT, with sustained values of several hundred $\mathrm{nT}$, as seen in Fig. 8, giving the signature typical of a convection bay. A further Pi2 signal and sharp decrease in $X$ component at the Alaskan stations and Dawson signaled a second onset at 10:00 UT, which may correlate with changes in the $Y$ component at Poste-de-la-Baleine that developed a Ps 6like character; however, the $Z$ component did not develop as would be expected in Ps 6. Due to sparsity of stations in eastern Canada, it is difficult to establish whether there was a correlation of Ps 6 initiation with this onset. Although other Pi2 bursts were observed around 12:00 UT, they may be found during convection bays in the absence of onsets (Sergeev et al., 2001). Absence of $\mathrm{Pi} 2$ pulsations was used in the original definition of the term convection bay by Pytte et al. (1978), but our ability to detect them may reflect the fact that modern instruments can detect lower levels of pulsations. In any case, sharply defined bays were not found in magnetic data to accompany these Pi2 bursts, and we conclude that onsets did not take place. In the absence of either onsets or Ps 6 activation, we conclude that, like the periods preceding Ps 6 activation in the events previously described, the period from 10:00 UT to 13:30 UT primarily featured steady convection.

A Ps 6 activation took place at 13:30 UT and was most clearly detected at College, as shown in Fig. 8. There was also a positive $Z$ perturbation there, indicating the onset currents to be south of College. A clear and sharp drop in the H-value at Alaskan station Talkeetna took place only at 13:38 UT, however, so the currents at 13:30 UT must have been close to College. Ps 6 disturbances initiated at College then and even more prominently at Fort Yukon to its north. Kotel'nyy station, on the 210 magnetic meridian, detected a sharp drop of about $190 \mathrm{nT}$ beginning at 13:30 UT. Pi2 signals for this period are weak at all stations, including those in China; thus, we cannot say for certain whether two onsets were involved or whether the delayed $X$ component decrease at Talkeetna was due to the motion of the electrojet. College, Dawson, and Fort Yukon further north were located under the electrojet and detected a clear Ps 6 signal, while the onset was at the southern border of the convection electrojet. This is consistent with the simple Ps 6 model of Kawasaki and Rostoker (1979), which features equatorward current flow over several degrees of magnetic latitude.

A mid-latitude Pi2 and the start of a decrease of over $200 \mathrm{nT}$ in $X$ at Ft. Yukon lead us to believe that a further onset took place at 14:24 UT. Little change in Ps 6 behavior was noted at this time. Sharp drops in $X$ at College and Dawson at 14:41 UT and 14:47 UT (respectively) correlated with changes in Ps 6 activity, the latter most notably at Fort Smith, where Ps 6 pulses of several hundred nT began at 14:47 UT. Several bursts of Pi2 activity took place during this time period. With northward turning at 15:40 UT, the magnetic activity declined rapidly and the Ps 6 pulse train died away. During this event, onsets at different latitudes affected the Ps 6 characteristics at stations near those latitudes. Onsets
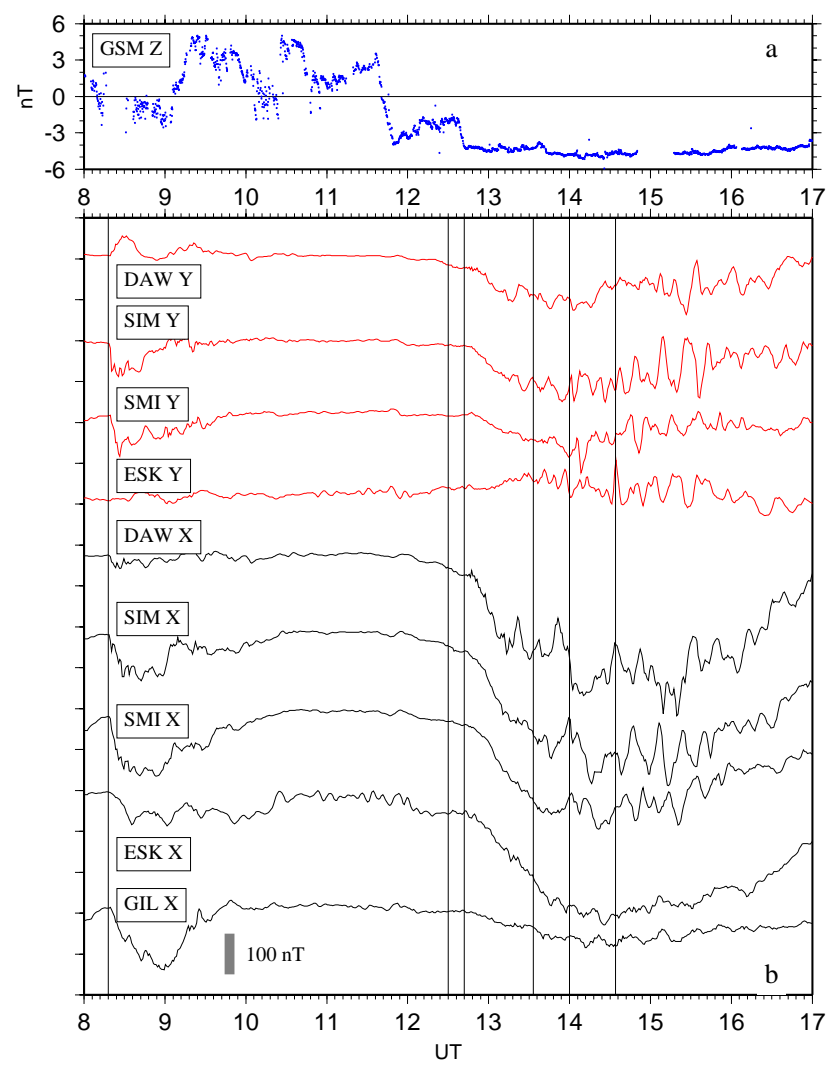

Fig. 9. (a) Northward component of interplanetary magnetic field as observed at the Wind spacecraft on 19 March 1999 and propagated to Earth at the solar wind velocity. (b) Overview of magnetic activity on 19 March 1999.

after a period of steady convection appeared to correlate with Ps 6 activation.

\subsection{March 1999 event}

The Wind, ACE, and IMP-8 spacecraft detected a period of about $15 \mathrm{~h}$ of generally southward IMF beginning on 19 March 1999. As corrected (a 3-min delay from IMP-8) for Earth arrival, this period began at 11:41 UT on 19 March. On that day, ACE indicated the solar wind density to remain close to a nominal 7 particles/cc and speed to remain near a moderate $375 \mathrm{~km} / \mathrm{s}$, the values that prevailed at southward turning. Until 23:00 UT, $B_{Z}$ (GSM) was steadily southward and approaching $-10 \mathrm{nT}$; the first part of this interval may be seen in Fig. 9. During the period 12:00 UT to 17:00 UT, there was little evident expansive phase activity, but pronounced convection bays as viewed by CANOPUS stations (see bottom panel of Fig. 9). In the interval 13:30 to 14:00 UT, about $2 \mathrm{~h}$ after the southward turning, clear Ps 6 signatures were seen to start at several stations in western North America. The lower panel of Fig. 10 shows a clear onset-like $X$ component signature at 13:36 UT at Kaktovik, located at about $70^{\circ}$ magnetic latitude on the northern shore of Alaska. The onset time as determined from mid-latitude $\mathrm{Pi} 2$ (average maximum amplitude $0.4 \mathrm{nT}$ ) was 13:34 UT. This high latitude event ap- 
pears to have had a close temporal connection to initiation of relatively low amplitude Ps 6 activity observed at Eskimo Point, 4 MLT zones eastward, as shown in the upper panel of Fig. 10. A positive $Z$ component of roughly $300 \mathrm{nT}$ observed at Kaktovik during the convection bay shows the station to have been north of the electrojet. The fact that both the onset and Ps 6 were associated with the poleward border is supported by the Alaska magnetic signatures, in each case very clear and with several hundred nT of perturbation, as shown in Fig. 11. At Fort Yukon and College, south of Kaktovik, near-zero and negative $Z$ signatures (respectively) were associated with the negative $X$ signatures, resulting from the westward electrojet during the convection bay. Similarly, bay signatures from the Churchill line of the CANOPUS array (some shown in Fig. 9) indicate that the westward electrojet's poleward border was located at about $70^{\circ}$ magnetic latitude. Other studies have found that the poleward border was host to the current systems associated with Ps 6 (Opgenoorth et al., 1983; Pellinen et al., 1992). Thus, our conclusion that the Ps 6 current is at the poleward border may not be surprising: however, the clear onset-like signature of several hundred nT observed at Kaktovik also suggests that the associated currents flowed only near the poleward border. We conclude that the ground signature, despite its resemblance to that of an EP onset, including having an associated Pi2, is instead associated with a PBI. (As noted above, Sutcliffe and Lyons (2002) have demonstrated other examples of PBIs with associated Pi2). Current clearly flowed near the poleward border for this onset and also for the associated Ps 6 system.

A second intensification at 14:00 UT is clear on the magnetograms from Alaska in Fig. 11, and we present evidence of the same intensification from Dawson, where the $X$ change was sharpest, in the bottom panel of Fig. 12. We did not detect an unambiguous $\mathrm{Pi} 2$ at the time of this intensification. A near-zero $Z$ component observed at Dawson and at College/Poker Flat suggests a central location in the auroral oval. Similarly Yellowknife was nearly central or slightly poleward of the centre of the electrojet, based on its $Z$ component (see Fig. 12). At this second onset time, typical Ps 6 disturbances initiated at Yellowknife.

For this event, we have shown two onset-Ps 6 initiation correlations within a short time of each other. In this case the first "onset" was apparently a PBI, and in both cases there was a latitudinal correspondence between the region of expansive phase onset and Ps 6 initiation. We revisit this event using radar data in Sect. 3 of this paper.

\subsection{Summary}

We have provided several examples in which Ps 6 initiation or change of character coincided temporally with expansive phase (EP) onset, as detected either nearby or to the west, in some cases many time zones westward. In these latter cases, at least, any initiation front travelling at the speed suggested by Saito (1978) would have taken many minutes to arrive, yet we find the Ps 6 activation to coincide with onset. This coincidence is well within the time uncertainty in these

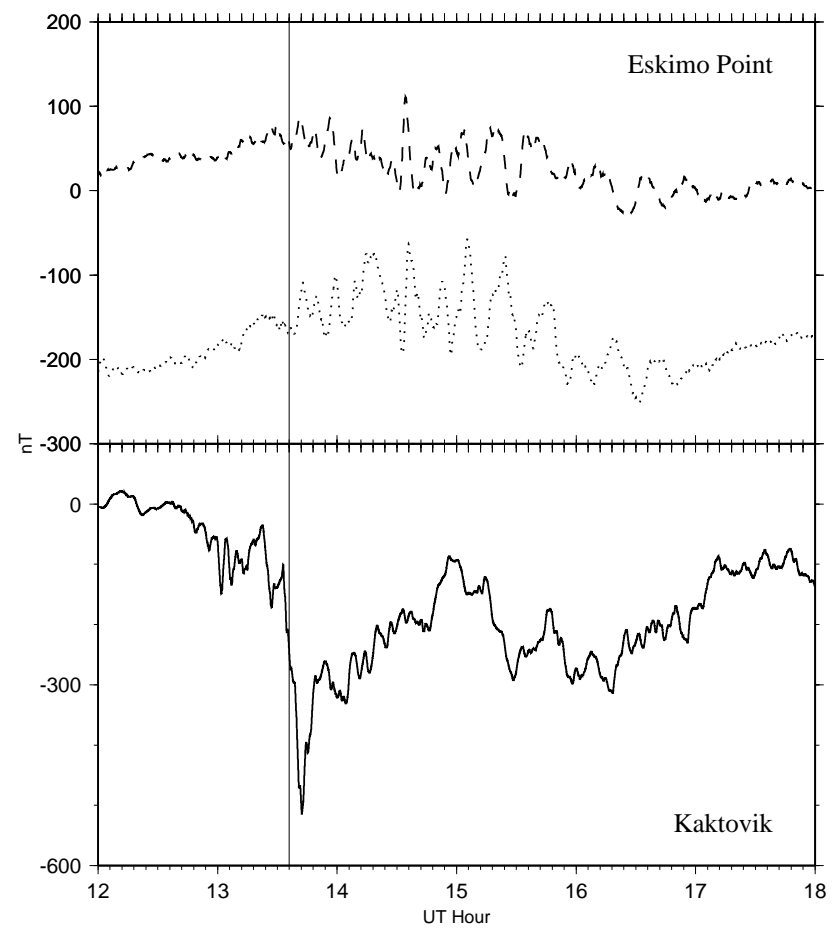

Fig. 10. $X$ component perturbations at at Kaktovik, Alaska (bottom), and $Y$ and $Z$ perturbations at Eskimo Point (top) on 19 March 1999, showing an extremely close correlation of onset time at 13:36 UT and Ps 6 initiation.

observations, including that due to the low frequency signals involved. These results are consistent with the observation of Mravlag et al. (1991) that Ps 6 disturbances simultaneously switched on over a wide longitudinal range, but go further in that we causally connect the Ps 6 activation or change of character to EP onsets. Ps 6 initiation seems to be essentially simultaneous with EP onset, even for stations distant from the onset region.

We have also found that onsets associated with Ps 6 initiation are located at the same relative position within the auroral oval as the currents associated with Ps 6 , and that the location may be equatorward, central to the auroral oval, or even at its poleward border. The last fact implies that PBIs may be associated with the initiation of Ps 6 trains. In the cases of strong Ps 6 signal near the centre of the oval, it is likely that the current systems extend to near the equatorward border, although we have not shown this here. This would be consistent with imaging observations (Connors and Rostoker, 1993), where localized patches of UV emission associated with upward field-aligned current were observed at the equatorward border of the auroral oval. Further, we note that in each case presented above, we found two separate latitudinal regions to be active. There have occasionally been observations of two latitudinally separated rows of omega bands being present in one all-sky imager field of view (Opgenoorth et al., 1994). Connors and Rostoker (1993) also noted a high latitude set of discrete features during an event of 3 May 1986, in addition to bright drifting 


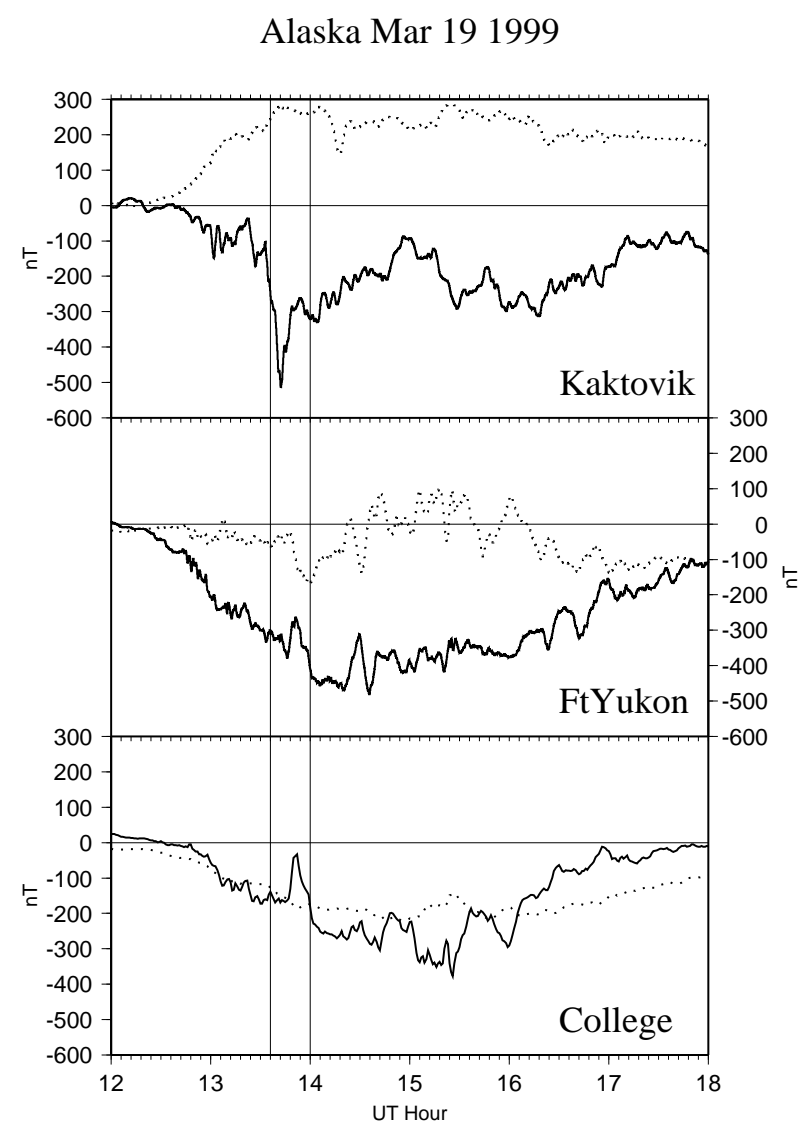

Fig. 11. $X$ (solid traces) and $Z$ (dotted traces) perturbations at stations College, Ft. Yukon, and Kaktovik, straddling the convection electrojet on 19 March 1999. The negative $X$ perturbation at all stations indicates a westward electrojet, and the negative $Z$ at College, near-zero $Z$ at Ft. Yukon, and positive $Z$ at Kaktovik confirm their respective locations near southern, central, and northern positions relative to the electrojet.

patches associated with Ps 6 at lower latitude. The KelvinHelmholtz instability mechanism can readily explain growth of two (or more) regions of growth of instability if there is more than one boundary at which shear can occur. We have shown that the onset and associated Ps 6 occur at the same latitude, and it is not inconsistent to claim that this common latitude marks a shear surface.

We have further concluded that activation at the poleward border is associated with PBI onset. In this case, however, and in distinction to the simultaneous EP onset and Ps 6 activation, there appears to be a delay from the time of PBI onset to that of Ps 6 activation. This is consistent with the claim of Saito, although it is not easy now to determine whether the cases he studied, in fact, dealt with PBI onsets or EP onsets.

\section{Discussion}

A common feature of the events studied here is that Ps 6 took place when the driven system was active, either in the

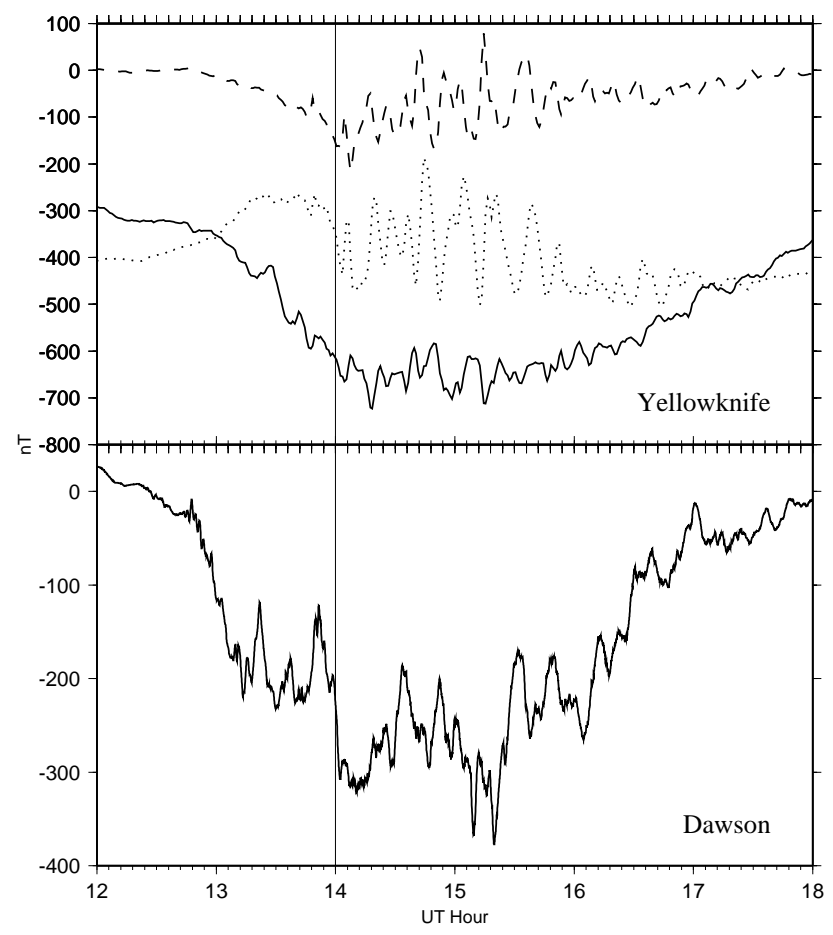

Fig. 12. $X$ perturbations at Dawson (bottom), and $X, Y$ and $Z$ perturbations at Yellowknife (top) on 19 March 1999, showing an extremely close correlation in time between a second onset at 14:00 UT and Ps 6 initiation.

aftermath of previous substorm activity or during a convection bay. Strong Ps 6 events seem to occur when convection is strong, corresponding to large electric fields in the ionosphere. A possible explanation for Ps 6 initiation being at the time of an onset would be a rapid increase in the morning sector electric fields at that time. Rostoker and Barichello (1980) considered the statistical aspects of Ps 6 in light of electric field measurements and particle precipitation and concluded that the electric field had a dominant influence in the formation of the Ps 6 current system. It is reasonable to infer that increased electric fields in the morning sector during periods of enhanced convection favors growth of the Kelvin-Helmholtz instability (KHI) and that this is associated with the Ps 6 current systems (Connors and Rostoker, 1993). This is reminiscent of a mechanism proposed by Rostoker et al. (1984) for an observed increase in Pc 5 pulsation power in the dawn sector associated with expansive phase onset. In addition, however, one must bear in mind that the magnetic signal is directly proportional to the electric current flowing in the ionosphere and that the current responds to both electric field and conductivity. It may be necessary to also invoke a role for sudden conductivity changes to explain the rapid appearance of the Ps 6 signal.

To investigate the role of the electric field at onset time in creating conditions for Ps 6 growth through the KelvinHelmholtz instability, we turned to radar data. The observed irregularity drift velocity is directly related to the electric field in such measurements (Lewis et al., 1997; Amm, 1996). 
Eskimo Point Vicinity Mar 191999

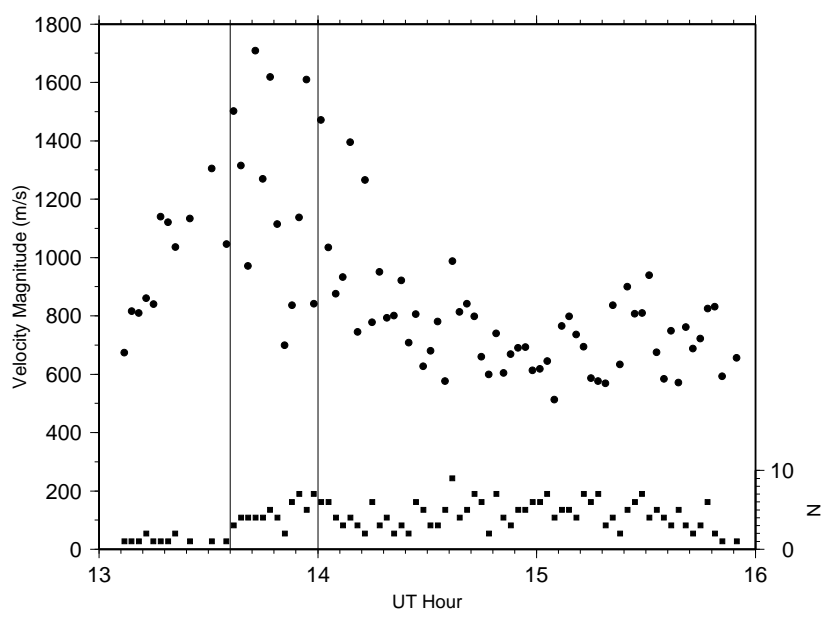

Fig. 13. Maximum velocity amplitudes from SuperDARN radar data for 19 March 1999 in the vicinity of Eskimo Point (data marked by circles, scale at left). The number of range-delay intersections contributing is marked by squares with scale at bottom right. Onset times of 13:36 UT and 14:00 UT are indicated by vertical lines.

We present in Fig. 13 radar measurements of maximum velocities over the Churchill CANOPUS line obtained by the joint Saskatoon and Kapuskasing SuperDARN HF radars (Greenwald et al., 1995) on 19 March 1999, when the event discussed in Sect. 2.4 (Figs. 9-12) took place. The HF radars attempt to detect echoes from the F-region of the ionosphere and vector velocity may be determined when both radars give good echo returns in a common target region. During the period shown, conditions for F-region detection appear to have been favorable, possibly since the onset in question is a PBI. During the Ps 6 event itself, echoes from Saskatoon alone show a pattern that is convincingly associated with an eastward-moving coherent field-aligned current system from many points within the antenna pattern. The merged data shown are, however, available only for a smaller number of intersections. Figure 13 shows data from two-minute scans for intersections between $88^{\circ}$ and $92^{\circ} \mathrm{W}$, and 58 and $64^{\circ} \mathrm{N}$. At 13:35 UT, very close to the time of the onset (likely PBI), the maximum flow velocity increased by about $50 \%$ (roughly $500 \mathrm{~m} / \mathrm{s}$ ) and remained high for roughly one hour. In addition, the number of cells from which strong echoes were detected increased significantly at the time of the onset, as seen in Fig. 13. The post-onset returns came from an average latitude of $61^{\circ}$ geodetic (about $70^{\circ}$ magnetic), which is the latitude of Eskimo Point, where the Ps 6 were observed to occur. Thus, the only significant and prolonged group of echo returns showing consistently very high velocities took place after onset time, and Ps 6 were observed to start at that time. To further clarify, we present in Fig. 14 the derived vector velocity set near onset time in a longitudinal range $\left(90^{\circ}\right.$ to $92^{\circ} \mathrm{W}$ ) close to Eskimo Point. This clearly shows the increased number of echo returns after onset time and also the
Merged Velocities Mar 191999 (-90 to -92 Longitude)

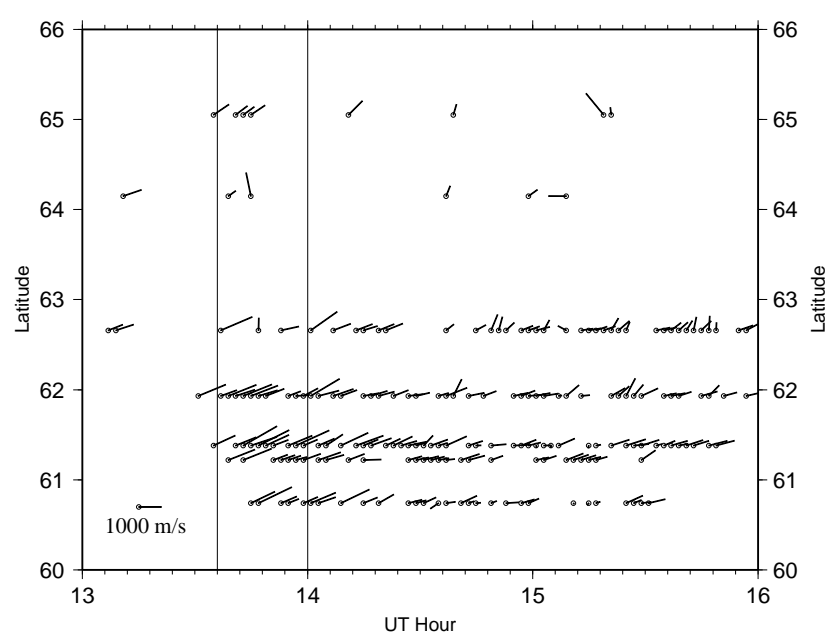

Fig. 14. Vector velocity of F-region ionospheric flow at the longitude nearest Eskimo Point, displayed as a function of UT and latitude for 19 March 1999. Onset times of 13:36 UT and 14:00 UT are indicated by vertical lines. Velocity magnitude scale is at lower left.

general ENE trend of the velocity vectors. The velocity azimuth throughout the post-onset period averaged $70^{\circ}$, and the velocities averaged $1000 \mathrm{~m} / \mathrm{s}$ in this generally eastward direction. The geometry is similar to that observed for a Ps 6 event by Wild et al. (2000) using the similar CUTLASS radar, although the flow velocities in our case are higher by a factor of two. Reversals to equatorward flow are not a prominent feature of our data set, although they were observed by Wild et al. (2000) as correlated with Ps 6 features. We do note variations in the north-south velocity component and more detailed examination has shown these to correlate with the passage of the Ps $6 Y$ component peaks over the magnetic station, showing a more northerly velocity at those times. Using $\boldsymbol{E}=-\boldsymbol{v} \times \boldsymbol{B}$ we find that these radar observations imply a nearly equatorward electric field of about $60 \mathrm{mV} / \mathrm{m}$. DE-2 observations of the region east of the auroral bulge during active times show an equatorward component of electric field of about this magnitude (Fujii et al., 1994). This average morning sector electric field and conductivity allow closure of field-aligned currents through Pedersen currents. The more northerly velocity component correlated with $Y$ component peaks implies that the southerly overhead electric currents associated with Ps 6 are Hall currents, as also concluded in the more detailed study by Wild et al. (2000) and earlier by Nielsen and Sofko (1982).

We have demonstrated that measured electric fields (as implied by velocities) were higher immediately after PBI onset in a case where Ps 6 were also observed to initiate at the onset time. However, we cannot exclude a large role for conductivity changes in the formation of the Ps 6 current system. Amm (1996) stresses that both electric fields and conductivity must play a role in determining the current system responsible for Ps 6. Our conclusion that the electric field was 
enhanced at onset at first appears to contradict observations of suppression of electric fields in pseudobreakups (Yeoman et al., 2000) and in onsets (Lewis et al., 1997). Those authors proposed that the electric field could be suppressed due to precipitation of energetic particles, enhancing conductivity and thus reducing electric fields, at onset. This would be expected in the midnight sector, where those studies were focused, but our measurements are in the morning sector. It may also be true that the precipitation mechanism for suppression of electric fields is active in some onsets, yet not in others. Our results show an enhancement of electric field in the morning sector at the time of an onset associated with Ps 6 disturbances. Since other studies find that the electric field in the midnight sector is suppressed at onset, we suggest that further study of global electric fields at the time of onsets is needed.

\section{Conclusion}

We have presented here evidence that Ps 6 initiation and onsets, both of substorm expansive phases and at the poleward border, may be linked in at least some cases. This evidence strengthens the arguments of Connors (1998) and Wild et al. (2000) of a causal link or common origin for these aspects of substorms. It reinforces the arguments of those authors that a wider-ranging and statistically meaningful study should be done. While there remain problems in the reliable detection of expansive phase onsets and these considerations likely apply to Ps 6 detection as well, ground magnetic records from the auroral zone at many longitudes are a means of starting such a study. We have also found analysis of midlatitude Pi2 to be helpful in accurate determination of onset times, including, in many cases, those of PBIs. Appropriate use of meridian chain data also provides a means of establishing the latitudinal position of the Ps 6 current system with respect to the auroral oval. "Onsets" used in a broad sense appear to take place at either the border of, or within, the auroral oval. Studies of other characteristics than the magnetic signatures which we have primarily used are needed to explore this problem further, but it is useful to note that Ps 6 initiation is a characteristic of what is likely to be two different "onset" processes (PBIs and expansive phase onsets). Global satellite images and particle measurements are useful adjuncts, and radar measurements such as those presented here and by Wild et al. (2000) can provide physical parameters relevant to the study of Ps 6 causation and growth. We expect that the theory of the Kelvin-Helmholtz instability can be used toward an observationally based theoretical understanding.

If a sequence of substorms or an SMC period occurs, Ps 6 activation may appear to be during the recovery phase, but may instead be associated with later expansive phase onsets if they cause growth of convection in the dawn sector. Ps 6onset association is consistent with the view of Connors and Rostoker (1993) and Wild and colleagues (2000) that Ps 6 result from the effects of KHI within the near-Earth magnetosphere. At the level of the ionosphere the implication is that a large morning sector convective flow velocity, or equivalently electric field, is needed for growth of the instability. The association of Ps 6 with onsets would be explained in this view if an increase in the electric field in the morning sector is a result of onsets (EP or PBI). It is not inconsistent that Ps 6 also occur at other times, nor may an important role for conductivity changes be excluded. Gaps in data may explain why it is often difficult to find onsets associated with Ps 6. Even if the onset association found here is commonplace, the data required from widely separated stations at the same relative location in the auroral oval may not be available to allow the association to be made for a particular event. On the other hand, it is likely that Ps 6 events also occur when convection is strong, in the absence of onsets. In all cases we have examined, the Ps 6 phenomenon took place during convection bays or steady magnetospheric convection. It may be that Ps 6 and omega bands should be added to the list of diagnostic characteristics of such intervals.

In a broader sense, the inclusion of Ps 6 when examining phenomenology of the growth and expansive phases, and poleward border intensifications, may be useful in coming to understand substorm onset. We also infer that Ps 6 may not be directly associated with recovery phase, but with any time when high convection velocities are present, which may include times when onset increases those velocities.

Acknowledgements. CANOPUS was constructed by, and is operated by, the Canadian Space Agency. Assistance from T. Hughes and J. Trickey with CANOPUS data is appreciated. The Athabasca magnetic station is operated in collaboration with C. T. Russell and P. Chi of UCLA, with funding from the Academic Research Fund of Athabasca University. Mid-latitude magnetic data was furnished by the UCLA Ground Magnetometer Data Center and we thank V. Angelopoulos, G. Reeves, Guan Le, M. Moldwin and C. T. Russell for use of the data. Preliminary ACE solar wind data were obtained through CDAWeb courtesy N. Ness, Bartol Research Institute, and D. J. McComas, LANL. Data have been used from the University of Alaska Geophysical Institute Magnetometer Array with thanks to J. Olson, and from the IMAGE array of the Finnish Meteorological Institute, with thanks to A. Viljanen. Images from POLAR UVI were used courtesy of G. Parks of the University of Washington and we acknowledge the help of G. Germany of the University of Alabama in Huntsville in their use. The 210 magnetic meridian (CPMN) data were supplied by the 210MM (CPMN) Observation Group (PI, K. Yumoto). MC and GR acknowledge the support of the Natural Sciences and Engineering Research Council (NSERC). Operation of the SuperDARN Kapuskasing radar is supported by NASA Grant NAG5-10597. The Canadian SuperDARN Saskatoon radar operation and scientific analysis have been supported by grants from NSERC Canada and contracts from the Canadian Space Agency (CSA). We thank D. André for help with SuperDARN data analysis. Model results used in CGM transformations were obtained from the web pages of NASA's Space Science Data Center. Graphics were produced using the GMT system (Wessel and Smith, 1991). MC thanks the Institute for Geophysics and Planetary Physics, University of California, Los Angeles, for hospitality during preparation of this article.

Topical Editor G. Chanteur thanks J. Wild and A. Jorgensen for their help in evaluating this paper. 


\section{References}

Akasofu, S.-I.: The Development of the Auroral Substorm, Planet. Space Sci. 12, 273-282, 1964.

Amm, O.: Improved electrodynamic modeling of an omega band and analysis of its current system, J. Geophys. Res. 101, 26772684, 1996.

Baker, D. N., Pulkkinen,T. I., Angelopoulos, V., Baumjohann, W., and McPherron, R. L.: Neutral Line Model of Substorms: Past Results and Present View, J. Geophys. Res. 101, 12 975-13 010, 1996.

Brittnacher, M., Spann, J., Parks, G., and Germany, G.: Auroral Observations by the Polar Ultraviolet Imager (UVI), Adv. Space Res. 20, 1037-1042, 1997.

Connors, M.: Auroral Current Systems Studied Using Automated Forward Modelling, Ph.D. Thesis, University of Alberta, pp. 427, 1998.

Connors, M. and Rostoker, G.: Source Mechanisms for Morning Auroral Features, Geophys. Res. Lett., 20, 1535-1538, 1993.

Fujii, R., Hoffman, R. A., Anderson, P.C., Craven, J. D., Sugiura, M., Frank, L. A., and Maynard, N. C.: Electrodynamic Parameters in the Nighttime Sector during Auroral Substorms, J. Geophys. Res. 99, 6093-6112, 1994.

Greenwald, R. A., Baker, K. B., Dudeney, J. R., Pinnock, M., Jones, T. B., Thomas, E. C., Villain, J.P., Cerisier, J.C., Senior, C., Hanuise, C., Hunsucker, R. D., Sofko, G., Koehler, J., Nielsen, E., Pellinen, R., Walker, A. D. M., Sato, N., and, Yamagishi, H.: DARN/SuperDARN: A Global View of the Dynamics of High Latitude Convection, Space Sci. Rev. 71, 761-796, 1995.

Henderson, M. G., Kepko, L., Spence, H.E., Connors, M., Sigwarth, J. B., Frank, L. A., Singer, H. J., and Yumoto, K.: The Evolution of North-South Aligned Forms into Auroral Torch Structures: The Generation of Omega Bands and Ps6 Pulsations via Flow Bursts, EOS Trans. AGU 82(47), Fall Meet. Suppl., Abstract SM51B-0809, 2001.

Jorgensen, A. M., Spence,H. E., Hughes, T. J., and McDiarmid, D.: A Study of Omega Bands and Ps 6 Pulsations on the Ground, at Low Altitude and at Geostationary Orbit, J. Geophys. Res. 104, 14 705-14 715, 1999.

Kawasaki, K. and Rostoker, G.: Perturbation Magnetic Fields and Current Systems Associated with Eastward Drifting Auroral Structures, J. Geophys. Res. 84, 1464-1480, 1979.

Kepko, L. and McPherron, R. L.: Comment on "Evaluation of LowLatitude Pi2 Pulsations as Indicators of Substorm Onset Using Polar Ultraviolet Imagery" by K. Liou et al., J. Geophys. Res. 106, 18 919-18922, 2001.

Kisabeth, J.L.: On Calculating Magnetic and Vector Potential Fields due to Large-Scale Magnetospheric Current Systems and Induced Currents in an Infinitely Conducting Earth, in: Quantitative Modeling of Magnetospheric Processes, (Ed) Olson, W. P., American Geophysical Union, Washington, pp. 473-498, 1979.

Koskinen, H.E. J., Lopez, R.E., Pellinen, R. J., Pulkkinen, T. I., Baker, D. N., and Bosinger, T.: Pseudobreakup and Substorm Growth Phase in the Ionosphere and Magnetosphere, J. Geophys. Res., 98, 5801-5813, 1993.

Lewis, R. V., Freeman, M.P., Rodger, A.S., Reeves, G.D., and Milling, D. K.: The Electric Field Response to the Growth Phase and Expansion Onset of a Small Isolated Substorm, Ann. Geophysicae, 15, 289-299, 1997.

Liou, K., Meng, C.-I., Lui, A. T. Y., Newell, P. T., Brittnacher, M., Parks, G., and Nosé, M.: A Fresh Look at Substorm Onset Identifiers, in: SUBSTORMS-4, (Eds) Kokobun, S. and Kamide, Y.,
Kluwer, Dordrecht, 249-252, 1998.

Lyons, L. R., Nagai, T., Blanchard, G. T., Samson, J. C., Yamamoto, T., Mukai, T., Nishida, A., and Kokubun, S.: Association Between Geotail Plasma Flows and Auroral Poleward Boundary Intensifications Observed by CANOPUS Photometers, J. Geophys. Res. 104, 4485-4500, 1999.

Mravlag, E., Scourfield, M. W. J., Walker, A. D. M., Sutcliffe, P. R., and Nielsen, E.: Simultaneous Observations of Omega Band Related Phenomena in Both Hemispheres, JATP 53, 309-317, 1991.

Nielsen, E. and Sofko, G.: Ps 6 Spatial and Temporal Structure from STARE and Riometer Observations, J. Geophys. Res., 87, 8157-8165, 1982.

Olson, J.: Pi2 Pulsations and Substorm Onsets: A Review, J. Geophys. Res., 104, 17 499-17 520, 1999.

Opgenoorth, H.J., Oksman, J., Kaila, K.U., Nielsen, E., and Baumjohann, W.: Characteristics of Eastward Drifting Omega Bands in the Morning Sector of the Auroral Oval, J. Geophys. Res., 88, 9171-9185, 1983.

Opgenoorth, H.J., Persson, M.A.L., Pulkkinen, T. I., and Pellinen, R. J.: Recovery Phase of Magnetospheric Substorms and its Association with Morning-Sector Aurora, J. Geophys. Res., 99, 4115-4129, 1994.

Pellinen, R. J., Opgenoorth, H. J., and Pulkkinen, T. I.: Substorm Recovery Phase: Relationship to Next Activation, Proc. Int Conf. Substorms (ICS-1), ESA SP-335, 469-475, 1992.

Press, W. H., Teukolsky, S. A., Vetterling, W. T., and Flannery, B. P.: Numerical Recipes in C, Second Edition, Cambridge University Press, Cambridge, 1992.

Pulkkinen, T. I., Baker, D. N., Fairfield, D. H., Pellinen, R. J., Murphree, J. S., Elphinstone, R. D., McPherron, R. L., Fennell, J. F., Lopez, R.E., and Nagai, T.: Modeling the Growth Phase of a Substorm Using the Tsyganenko Model and Multi-Spacecraft Observations: CDAW-9, Geophys. Res. Lett., 18, 1963-1966, 1991a.

Pulkkinen, T.I., Baker, D. N., Frank, L. A., Sigwarth, J. B., Opgenoorth, H. J., Greenwald, R., Friis-Christensen, E., Mukai, T., Nakamura, R., Singer, H., Reeves, G. D., and Lester, M.: Two Substorm Intensifications Compared: Onset, Expansion, and Global Consequences, J. Geophys. Res., 103, 15-27, 1998.

Pulkkinen, T. I., Pellinen, R. J., Koskinen, H. E. J., Opgenoorth, H. J., Murphree, J. S., Petrov, V., Zaitzev, A., and Friis-Christensen, E.: Auroral Signatures of Substorm Recovery Phase: A Case Study, in: Magnetospheric Substorms, (Eds) Kan, J. R., Potemra, T. A., Kokobun, S., and Iijima, T., American Geophysical Union, Washington, 333-339, 1991 b.

Pytte, T., McPherron, R. L., Hones, E. W., and West, H. I.: Multiplesatellite Studies of Magnetospheric Substorms: Distinction Between Polar Magnetic Substorms and Convection-driven Negative Bays, J. Geophys. Res., 83, 663-679, 1978.

Rostoker, G.: Identification of Substorm Expansive Phase Onset, J. Geophys. Res., in press, 2002.

Rostoker, G. and Barichello, J.C.: Seasonal and Diurnal Variation of Ps 6 Magnetic Disturbances, J. Geophys. Res., 85, 161-163, 1980.

Rostoker, G., Spadinger, I., and Samson, J. C.: Local Time Variation in the Response of Pc5 pulsations in the Morning Sector to Substorm Expansive Phase Onsets near Midnight, J. Geophys. Res., 89, 6749-6757, 1984.

Saito, T.: Examination of the Models for the Substorm-Associated Magnetic Pulsation, Ps 6, The Science Reports of the Tôhoku University Series 5, Geophysics, 22, 2, 35-59, 1974.

Saito, T.: Long-Period Irregular Magnetic Pulsation, Pi3, Space Sci. 
Rev. 21, 427-467, 1978.

Samson, J. C.: Geomagnetic Pulsations and Plasma Waves in the Earth's Magnetosphere, in: Geomagnetism, Vol. 4, (Ed) Jacobs, J., Academic Press, New York, pp. 481-592, 1991.

Sergeev, V. A., Kubyshkina, M. V., Liou, K., Newell, P. T., Parks, G., Nakamura, R., and Mukai, T.: Substorm and Convection Bay Compared: Auroral and Magnetotail Dynamics During Convection Bay, J. Geophys. Res., 106, 18 843-18 855, 2001.

Sergeev, V. A., Pellinen, R. J., and Pulkinnen, T. I.: Steady Magnetospheric Convection: A Review of Recent Results, Space Sci. Rev., 75, 551-604, 1996.

Sutcliffe, P. R. and Lyons, L. R.: Association between quiet-time
Pi2 pulsations, poleward boundary intensifications, and plasma sheet particle fluxes, Geophys. Res. Lett., in press, 2002.

Wessel, P. and Smith, W. H. F.: Free Software helps map and Display Data, EOS Trans., AGU, 72, 441, 1991.

Wild, J. A., Yeoman, T. K., Eglitis, P., and Opgenoorth, H. J.: Multiinstrument observations of the electric and magnetic field structure of omega bands, Ann. Geophysicae, 18, 99-110, 2000.

Yeoman, T.K., Lewis, R. V., Khan, H., Cowley, S.W.H., and Ruohoniemi, J.M.: Interhemispheric Observations of Nightside Ionospheric Electric Fields in Response to IMF $B_{z}$ and $B_{y}$ Changes and Substorm Pseudobreakup, Ann. Geophysicae, 18, 897-907, 2000. 